\title{
Inovação nos cursos de ciências contábeis: Uma análise no catálogo de teses e dissertações da CAPES
}

\author{
Innovation in accounting science courses: An analysis in the CAPES thesis and dissertations catalog \\ Cursos de innovación en ciencias contables: Un análisis en el catálogo de tesis y disertaciones de
} CAPES

Recebido: 24/04/2021 | Revisado: 01/05/2021 | Aceito: 06/05/2021 | Publicado: 21/05/2021

\author{
Faber Brum da Costa \\ ORCID: https://orcid.org/0000-0001-9702-425X \\ Universidade Franciscana, Brasil \\ E-mail: faberbcosta@yahoo.com.br \\ Eliane Aparecida Galvão dos Santos \\ ORCID: https://orcid.org/0000-0002-3982-7297 \\ Universidade Franciscana, Brasil \\ E-mail: elianeaglavao1@gmail.com
}

\begin{abstract}
Resumo
O tema inovação no ensino aplicado ao curso de ciências contábeis é complexo e precisa ser discutido para além da aplicação estratégias tecnológicas, essa repercussão exige reflexão sobre ensinar e aprender. Desta forma, partiu-se da produção do estado do conhecimento para a realização de um mapeamento a fim de analisar as produções científicas produzidas que tratam o tema inovação no curso de ciências contábeis. Entende-se que o estudo se faz necessário pela amplitude do novo contexto educativo, em que a inovação é imprescindível para a melhoria da qualidade do ensino e da aprendizagem, nesse caso, nos cursos de graduação em Ciências Contábeis. Para compreender melhor o contexto em pauta, foi realizada uma pesquisa exploratória sobre o tema. Portanto, a seguir apresenta-se um estudo sobre o estado do conhecimento, com a finalidade de verificar as pesquisas relevantes já existentes, ou as lacunas de pesquisa acerca da inovação no ensino referente ao curso de graduação em Ciências Contábeis. Ao final da pesquisa constatou quer existem poucas publicações que tratam do tema inovação com a plenitude ao curso de ciências contábeis.
\end{abstract}

Palavras-chave: Ensino superior; Inovação; Estado do conhecimento.

\begin{abstract}
The theme of innovation in teaching applied to the accounting science course is complex and needs to be discussed in addition to applying technological strategies, this repercussion requires reflection on teaching and learning. In this way, we started from the production of the state of knowledge to carry out a mapping in order to analyze the scientific productions produced that deal with the theme of innovation in the course of accounting sciences. It is understood that the study is necessary due to the breadth of the new educational context, in which innovation is essential for improving the quality of teaching and learning, in this case, in undergraduate courses in Accounting. To better understand the context in question, an exploratory research on the topic was carried out. Therefore, the following is a study on the state of knowledge, with the purpose of verifying the relevant research already existing, or the research gaps about innovation in teaching related to the undergraduate course in Accounting. At the end of the research it was found that there are few publications that deal with the theme of innovation with fullness in the course of accounting sciences.
\end{abstract}

Keywords: University education; Innovation; State of knowledge.

\section{Resumen}

El tema de la innovación en la docencia aplicada a la carrera de ciencias contables es complejo y necesita ser discutido además de aplicar estrategias tecnológicas, esta repercusión requiere una reflexión sobre la enseñanza y el aprendizaje. De esta manera, partimos de la producción del estado del conocimiento para realizar un mapeo con el fin de analizar las producciones científicas producidas que abordan el tema de la innovación en el curso de las ciencias contables. Se entiende que el estudio es necesario por la amplitud del nuevo contexto educativo, en el que la innovación es fundamental para mejorar la calidad de la enseñanza y el aprendizaje, en este caso, en las carreras de grado en Contaduría. Para comprender mejor el contexto en cuestión, se llevó a cabo una investigación exploratoria sobre el tema. Por tanto, a continuación se realiza un estudio sobre el-estado del conocimiento, con el fin de verificar las investigaciones relevantes ya existentes, o las brechas de investigación sobre innovación en la docencia relacionadas con la carrera de Grado en Contabilidad. Al final de la investigación se encontró que existen pocas publicaciones que aborden el tema de la innovación con plenitud en el curso de las ciencias contables.

Palabras clave: Enseñanza superior; Innovación; Estado del conocimiento. 


\section{Introdução}

$\mathrm{O}$ processo de ensinar passa por transformações, especialmente no que se refere à tecnologia. Em outros tempos, o aprendizado ficava vinculado diretamente às aulas expositivas, com o conhecimento ligado, diretamente, ao que vinha de informações dos professores. Os tempos passaram e os avanços da tecnologia, bem como os sujeitos aprendentes exigem novos modos de pensar e realizar o ensino. A nova geração é altamente tecnológica, além disso, uma alta sobrecarga de atividades vem modificando o cotidiano da sociedade. Atualmente, o que se explana em sala de aula, muitas vezes, são acessados em tempo real por aparelhos eletrônicos, como celulares, computadores etc., essa exposição a tudo, em todos os lugares ao mesmo tempo, vem trazendo o desafio de transformar as formas de ensinar.

Nesse sentido, faz-se importante conhecer aquilo que está sendo produzido no campo da pesquisa sobre a inovação do ensino, especialmente na área das ciências contábeis. Por meio de um estudo dessa categoria, poderá, então, ser evidenciado os principais referenciais que vem subsidiando o tema inovação no ensino em cursos de Ciências Contábeis, conhecer os tipos de metodologias e instrumentos para coleta de dados utilizados, além de evidenciar o que está sendo produzido nos últimos anos sobre o referido tema. A partir dessa problemática e observando o atual cenário que se apresenta, bem como a pesquisa maior de dissertação, destaca-se o seguinte objetivo: mapear e analisar as produções Científicas publicadas sobre o tema inovação do ensino no campo das Ciências Contábeis em cursos de graduação e como essa temática busca-se identificar produções no contexto investigativo do estado do conhecimento.

A fim de estruturar este estudo, o primeiro item a ser explorado é o "Referencial Teórico", focando na questão das inovações no ensino do Curso Superior de Ciências Contábeis. Nesse é discutido, baseado nas teorias de Anastasiou e Alves (2015), o que se compreende por ensino e aprendizagem, bem como é pensado sobre os processos e estratégias de ensino que auxiliem o aluno na aquisição de conhecimento. Além disso, há a reflexão de como isso pode ser desenvolvido no Curso de Ciência Contábeis. Na sequência, em "Desenvolvimento", é apresentado como a pesquisa foi feita levando em conta as dissertações publicadas de 2015 a 2019, considerando, para análise, os seguintes descritores: Curso de Ciências Contábeis, Ensino Superior e Inovação no Ensino. Por fim, nas "Considerações finais", há uma retomada dos aspectos importantes discutidos ao longo deste trabalho.

\section{Metodologia}

A investigação realizada foi com base em um mapeamento do tipo "Estado do Conhecimento" acerca da inovação no ensino no superior no curso de ciências contábeis, especificamente nos descritos Curso de Ciências Contábeis, Ensino Superior e Inovação no ensino. Segundo Ens e Romanowski (2006, p. 43), o estado do conhecimento tem como intuito realizar um "[...] levantamento e uma revisão do conhecimento produzido sobre um tema". Os autores, também, apontam que as pesquisas do Estado do Conhecimento.

[...] favorecem a compreensão de como se dá a produção do conhecimento em uma determinada área em teses de doutorado, dissertações de mestrado, artigos de periódicos e publicações. [...] Essas análises possibilitam examinar as ênfases e temas abordados nas pesquisas; os referenciais teóricos que subsidiaram as investigações; a relação entre o pesquisador e a prática pedagógica; as sugestões e proposições apresentadas pelos pesquisadores; as contribuições da pesquisa para mudança e inovações da prática pedagógica; a contribuição dos professores/pesquisadores na definição das tendências do campo de formação de professores. (Romanowsk; ENS, 2006, p. 39).

É de suma importância fazer um levantamento e uma análise dos trabalhos já produzidos na área da Ensino no curso de ciências contábeis antes de realizar uma investigação, neste caso, tendo em vista que a temática em estudo tem relevância na inovação do referido curso. Nesta direção, realizou-se um mapeamento dos trabalhos, a partir de uma abordagem qualitativa e da análise de conteúdo, com o objetivo de reconhecer e compreender as contribuições das produções selecionadas. 
O corpus do estudo sobre o qual incidiu a pesquisa é composto de uma análise dos trabalhos completos apresentados em periódico da CAPES nos referidos anos (2015 a 2019). Na busca pelos trabalhos, foram utilizados critérios como: estar relacionado ao curso de ciências contábeis, apresentar discussões relacionadas à inter-relação a inovação no curso, realizou-se uma classificação temática a fim de mapear, de forma mais objetiva, a produção neste período. Posteriormente, utilizou-se dos preceitos da análise de conteúdo para proceder a análise dos trabalhos encontrados. Bardin (2009) conceitua a análise de conteúdos como:

Um conjunto de técnicas de análise das comunicações visando obter, por procedimentos, sistemáticos e objetivos de descrição do conteúdo das mensagens, indicadores (quantitativos ou não) que permitam a inferência de conhecimentos relativos às condições de produção/recepção (variáveis inferidas) destas mensagens. (p. 44)

Compreende-se que a análise de conteúdo é uma técnica de análise de dados produzidos em uma pesquisa, utilizada para analisar e interpretar as informações obtidas e relacionadas com o problema e objetivos da pesquisa. Assim, nesta etapa, foram analisados os trabalhos com as seguintes palavras-chave Ensino Superior. Inovação no ensino de ciências contábeis.

\section{Resultados e Discussão}

\section{Inovações no Ensino Superior: Curso de Ciências Contábeis}

Para entender as questões do ensino é necessário pensar e discutir sobre ensino e aprendizagem compreendendo-os como um processo evolutivo, ativo e que possibilite autonomia na busca pelo conhecimento. Esse processo está passando por uma reflexão crítica sobre a realização dos modelos tradicionais. Anastasiou e Alves (2015) discutem aspectos da ação do docente, referindo-se que as ações de ensinar e aprender são, muitas vezes, consideradas e executadas como ações disjuntas, decorrentes de uma ideia de que ensinar é apresentar ou explicar o conteúdo, em uma exposição, em que grande parte, dos docentes, que procuram fazê-la com o máximo de habilidade. Essa é uma visão de ensino tradicional, no qual a “[...] aula é o espaço em que o professor fala, diz, explica o conteúdo, e compete ao aluno anotá-lo para depois memorizá-lo. Daí pode prescindir da presença própria do aluno pois, se há um colega que copia tudo, basta fotocopiar suas anotações e estudá-las, a fim de memorizar conteúdos" (Anastasiou; Alves 2015, p. 17). Quando se trabalha para que o aluno se aproprie do conhecimento para além do simples repasse da informação, é preciso, assim, que o professor se reorganize na direção do aprender. "Nessa perspectiva, atua a necessidade de ensinar o estudante a apreender" (Anastasiou; Alves 2015, p. 17).

Nem sempre o que é ensinado é apreendido, resultando em lacunas que, certamente, trarão dificuldades à evolução do aprendizado do discente. Baseado no ponto de vista que aprender e apreender não contemplam o mesmo sentido, Anastasiou e Alves (2015) definem o termo ensinar como: processos de ensinagem usado para refletir e nortear as práticas de ensino. Assim as autoras dizem que

[t]rata-se de uma ação de ensino da qual resulta a aprendizagem do estudante, superando o simples dizer do conteúdo por parte do professor, pois é sabido que na aula tradicional, que se encerra numa simples exposição de tópicos somente há garantia da citada exposição, e nada se pode afirmar acerca da apreensão do conteúdo pelo aluno. Nessa superação da exposição tradicional como única forma de explicar os conteúdos é que se inserem as estratégicas de ensinar (Anastasiou; Alves, 2015, p. 20).

Nesse conceito, as autoras trazem importantes posicionamentos sobre como funciona os processos de ensinar, abrindo uma grande reflexão sobre a necessidade de envolver o aluno na busca do conhecimento. Este envolvimento é imprescindível para a concretização das fases de ensinar e apreender. Para tanto, essas precisam ser planejadas e implementadas, por meio de estratégias de ensino que desenvolvam as diversas competências necessárias para a formação do futuro profissional. 
O processo de apreensão, de conhecer, está relacionado com o enredar, estabelecendo os nós necessários entre os fios a serem tecidos. Para dar conta desse "enredamento", há que se superar as dificuldades, vencendo a simples memorização de conteúdo repassado pelo professor (Anastasiou; ALVES, 2015). Nesse sentido, as práticas da aula universitária acenam para a necessidade de repensar os modos de ensino e aprendizagem. Por essa razão, quando as autoras referem-se que é preciso vencer a simples memorização, elas estão desafiando os docentes a proporem estratégias inovadoras de ensino.

Para Anastasiou e Alves (2015) o termo "estratégias de ensino" refere-se aos meios utilizados pelos docentes para promover o processo de ensino, de acordo com cada atividade e os resultados esperados. Assim, as autoras referem que

[a]s estratégias visam à consecução de objetivos, portanto, há que ter clareza sobre aonde se pretende chegar naquele momento com o processo de ensinagem. Por isso, os objetivos que norteiam devem estar claros para os sujeitos envolvidos - professores e alunos - e estar presentes no contrato didático, registrado no Programa de Aprendizagem correspondente ao módulo, fase, curso, etc. (Anastasiou; Alves, 2015, p. 71).

Nesse contexto, Pimenta e Anastasiou (2014) alertam que o professor, ao confrontar suas ações cotidianas com as produções teóricas, propõe-se a revisão de suas práticas e das teorias que lhes dão por base. Nessa lógica, o professor, através de pesquisas, busca novas práticas que possam auxiliar na obtenção de novos conhecimentos por parte dos alunos. Por isso, as transformações das práticas docentes só se efetivam à medida que o professor amplia sua consciência sobre a própria prática dentro da sala de aula.

Dentro do conceito apreender, o professor tem um grande papel, para o desenvolvimento dos estudos no curso de Ciências Contábeis. Dessa forma, ele precisa criar estratégias que permitam relacionar os complexos conteúdos, em que as dimensões das disciplinas estão pautadas, para aulas mais leves, em que o modelo tradicional passa ser uma pequena parte no processo. Assim, visa-se a busca por metodologias mais interativas para o universo do estudo de contabilidade, promovendo, o professor, um papel de orientador e não um simples expositor de conteúdo. Para tanto, exige-se "[...] do professor enorme competência em seu papel orientador, pois é necessário que ele esteja, permanentemente, atento para promover a ajuda adequada ao momento do processo em que se localiza o educando, visto que conhecer não é adivinhar" (Grillo; Lima, 2008, p. 28).

O papel do professor, no desenvolvimento da construção do conhecimento dos estudantes, é definido por estimular a construção do objetivo de aprendizagem. Está vinculado, então, a escolha de estratégias para estabelecer os vínculos aos nexos dos conteúdos desenvolvidos, à problematização e à busca do objeto a ser conhecido. Isso pode ser feito por meio de ações como: "estudo de textos, vídeos, pesquisa, estudo individual, debates, grupos de trabalhos, seminários, exercícios, nos quais se explicitam as relações que permitem identificar, pela análise, como o objetivo de conhecimento se constitui" (Anastasiou; Alves, 2015, p. 37).

Ao estudo que está definido por identificar medidas inovadoras, presentes no contexto educacional de ensino do curso de Ciências Contábeis, é imprescindível fazer uma relação do processo de ensinar dentro da associação do que é o papel do professor em sala de aula. Tem-se, atualmente, abordagens inovadoras, que podem ser realizadas na sala de aula. Mas essas dependem da atuação dos professores para que o ensino seja inovador, pois se o aluno não for envolvido nessa dinâmica mais ativa, onde ele participe e faça as aulas acontecerem, esse ensino pode não se constituir como inovador. Para Cunha (2016, p. 92), "muitas vezes a inovação é compreendida como a inclusão de aparatos digitais e tecnológicos nas instituições de ensino. Entretanto, essa é uma forma reducionista de abordar o tema". Nesse sentido, são necessárias mudanças nas metodologias tradicionais. Masetto (2003) atribui que a inovação vem tomando novo formato à medida que as concepções mais antigas não conseguem se sustentar com as novas demandas da sociedade. Acrescenta ainda que a

[...] inovação e mudanças andam juntas, mas só acontecem de fato quando as pessoas nelas envolvidas se abrem para aprender, para mudar, para adquirir novos conhecimentos, para alterar conceitos e ideias [sic] trabalhadas, tem muitos 
anos, para assumir novos comportamentos e atitudes não comuns até aqueles momento, para mudar suas próprias crenças e aderir a novas e fundamentais maneiras de pesar (Masetto, 2003, p. 200-201).

Anastasiou e Alves (2015) ressaltam que a proposta atual, no processo de ensinagem, está diretamente ligada à ação de apreender, tendo como meta a apropriação tanto do conteúdo como do processo. Assim, orientações pedagógicas não se referem mais a passos a serem seguidos e sim a momentos a serem construídos pelos sujeitos em ação.

O professor do ensino superior de Ciências Contábeis e a prática de novas atualizações formulam o nosso universo tecnológico, constituindo inúmeras maneiras inovadoras de ensinar. Inovação, no ensino superior, é um conceito em destaque, discutido nas diversas instâncias das universidades. O termo inovação tem total relevância no que se refere à educação e ao novo formato de ensinar. Destarte, trabalhar com o conhecimento refere-se a um processo sistematizado de pensamentos, no qual colocam-se, em ação, diferentes operações, encadeando uma crescente complexidade no que se refere a ensinar. Assim, as autoras destacam que

Num estudo sobre operações de pensamentos, encontra-se o pensar como forma elos fatos, estudando-os em direção aos objetivos, havendo assim um caráter intencional, ou seja, ao selecionar as ações contidas em diferentes estratégias, o programa de aprendizagem propõem ao aluno o exercício de processos mentais de complexidade variada e crescente à observação, à tomada de decisões tendo como inferência como operações mentais e racionais tendo julgamento e conclusão (Anastasiou; Alves 2015, p. 31).

Ao pensar a elaboração dos programas do Curso de Ciências Contábeis, as contribuições das autoras são importantes, pois Anastasiou e Alves (2015, p. 36) sugerem momentos a serem considerados no trabalho da construção do conhecimento. O primeiro diz respeito a considerar a prática social do aluno, como ponto de partida, e sua percepção da realidade para a sala de aula. Destarte, a prática social será problematizada e submetida a um processo crítico de questionamento. O segundo momento é a interiorização dos novos elementos pela catarse. Tendo, por fim, uma prática reelaborada, permitindo ao aluno a construção de novos elementos com os conteúdos apreendidos, por situações elaboradas conjuntamente entre professor e aluno.

Desse modo, o estudante aprende com situações concretas, e pouco a pouco consegue ampliar o conhecimento. O aprendizado é formado a partir de ideias ou teorias para desenvolvê-las no concreto da profissão. É preciso formar profissionais, “[...] não apenas para nos adaptarmos à realidade, mas, sobretudo, para transformar, para nela intervir, recriandoa" (Freire, 1996, p. 28).

Dentro da inserção do que é inovação do ensino para os futuros bacharéis de Ciências Contábeis, é importante tratar, em uma breve fundamentação, do que são metodologias ativas. Berbel (2011) pontua que essas colocam o estudante em ação. O autor refere-se que

[a]s metodologias ativas têm o potencial de despertar a curiosidade, à medida que os alunos se inserem na teorização e trazem elementos novos, ainda não considerados nas aulas ou na própria perspectiva do professor. Quando acatadas e analisadas as contribuições dos alunos, valorizando-as, são estimulados os sentimentos de engajamento, percepção de competência e de pertencimento, além da persistência nos estudos (Berdel, 2011, p. 28).

Segundo (Charlot, 2010, p. 93). “a inovação não vale por si só, depende do conteúdo da inovação. Existem inovações ruins, existem inovações boas". As metodologias ativas são meios para promover a inovação nos processos de ensino, que incluem muitas discussões sobre as questões epistemológicas que as sustentam e as particularidades de um contexto coletivo. Para discutir o processo de inovação é importante trazer a asserção à tecnologia, que está cada vez mais presente, em um complexo universo de inovação, e vem rompendo o tradicional ambiente de ensino. Conforme Toebe (2016), as tecnologias educacionais apresentam possíveis mudanças e melhorias no processo de formação inicial de professor, pois permitem a inovação metodológica e curricular. Para ela, a integração das tecnologias educacionais requer ações 
Os alunos deverão ser iniciados também na utilização da tecnologia, para resolver problemas concretos que ocorrem no cotidiano de suas vidas. A aprendizagem precisa ser significativa, desafiadora, problematizadora e instigante, a ponto de modificar o aluno e o grupo, levando a buscar soluções possíveis para serem discutidas e concretizadas à luz de referenciais teóricos e práticos (Behrens, 2005, p. 77).

Tidd, Bessant e Pavitt (2008) apontam que ao se falar em práticas inovadoras, deve-se considerar que estas passam pelo repensar a forma como se olha para o que se apresenta na realidade atual, para o novo, e, principalmente, para o que ainda não foi pensado.

Trazer o novo para as salas de aula tem sido um grande desafio aos professores no universo acadêmico. A inovação vem compor a vida em sala de aula, e a tecnologia tem sido o grande fator da inovação, proporcionando atividades práticas, motivando professores e alunos em sala de aula. Segundo Masetto (2012, p. 15),

[d]denomina-se inovação as novidades da era tecnológica da informação e da comunicação, as novas condições para o conhecimento, o interesse em superar a fragmentação nos diversos campos conhecimento, a busca de um saber interdisciplinar, as recentes revisões das carreiras e dos perfis profissionais, até as demandas que o século XXI dirige à educação em seus diferentes ângulos.

A tecnologia está cada vez mais presente nas relações e no dia a dia dos alunos dos Cursos de Ciências Contábeis, porém precisam ser mais direcionadas para fins pedagógicos, ou seja, como meio para o ensino. As relações interpessoais se adaptaram a esse novo modo de se comunicar, a forma tradicional de comunicação vem dando lugar a uma nova sistemática da comunicação. Porém, não é apenas nesse campo que a inovação ganha espaço. Atualmente, tecnologia e educação têm andado lado a lado, de modo a auxiliar e aumentar o modo de aprendizagem. Assim,

[...] as metodologias ativas dão ênfase ao papel protagonista do aluno, ao seu envolvimento direto, participativo e reflexivo em todas as etapas do processo, experimentando, desenhando, criando, com orientação do professor; a aprendizagem [...] destaca a flexibilidade, a mistura e compartilhamento de espaços, tempos, atividades, materiais, técnicas e tecnologias que compõem esse processo ativo (Bacich, 2018, p. 4).

Analisar os desafios dos professores no ensino superior nos cursos de Ciências Contábeis, em uma reflexão do que foi e o que é o ensino superior, nos remete a rever conceitos e os modelos do ensinar. A sociedade está passando por grandes transformações na forma de pensar e acumular o conhecimento. Um universo de indivíduos conectados globalmente, fazendo com que a distância deixe de ser empecilho, transformando as tradicionais formas de ensinar em predestinadas estruturas informais de ensinar e aprender. Os momentos atuais são desafiadores para o docente. Não há como retroceder o template tecnológico de ensinar, em que o a tecnologia está destinada a fazer parte das formas de ensinar contabilidade aos alunos do ensino superior.

As metodologias ativas ${ }^{1}$ no ensino de Ciências Contábeis projetam-se para várias formas de dinamizar o ensino. Delinear o ensino na vida do aluno com a personalização da aprendizagem tem trazido muitas contribuições para o professor enfrentar os desafios do ensino superior. Descobrir como os alunos estão inseridos em seus universos pessoais e profissionais, dentro do seu projeto de vida, e utilizar a personalização do aprendizado contribuem para o planejamento e realização das atividades de ensino. Ademais,

[a] personalização encontra seu sentido mais profundo quando o estudante se conhece melhor e amplia a percepção do seu potencial em todas as dimensões. O projeto de vida é um componente curricular transversal importante, que visa a

\footnotetext{
${ }^{1}$ Metodologias ativas são estratégias de ensino centradas na participação efetiva dos estudantes, na construção do processo de aprendizagem, de forma flexível, interligada [...]. As metodologias ativas, num mundo conectado e digital, expressam-se por meio de modelos de ensino híbridos, com muitas possíveis combinações. A junção de metodologias ativas com modelos flexíveis e híbridos traz contribuições importantes para o desenho de soluções atuais para os aprendizes de hoje (Bacich \& Moran 2018, p. 4).
} 
promover a convergência, de um lado, entre os interesses e paixões de cada aluno e, de outro, entre seus talentos, história e contexto (Bacich \& Moran 2018. p. 5).

A busca do aprender ao ser motivado e ter um significado, a partir da própria motivação pessoal, conduz à reflexões mais profundas do sentido do que estamos aprendendo e como estamos aprendendo. No contexto do curso de graduação, todos os professores e todas as atividades de ensino e aprendizagem podem contribuir para que cada aluno se conheça melhor, oriente-se de forma mais consciente e autônoma.

O professor assume o papel de acompanhar mais de perto os alunos, ajudando-os a descobrirem seus interesses, talentos e fragilidades e a tomar decisões para modificar sua visão de mundo e desenhar caminhos para o futuro (Bacich e Moran 2018). As tecnologias digitais contribuem nesse processo, viabilizando os meios para um ensino com mais dinamismo, aprendizagens de compartilhamento comum e de introdução de novos produtos, processos e relações (Bacich e Moran 2018).

A diversidade de estratégias de ensino, se bem equilibradas e adaptadas entre o individual e o coletivo, podem mobilizar o aprendizado dos estudantes. Cada estratégia, situações problemas, projetos, design, jogos, narrativas, aprendizagem baseada em projetos ou em problemas ${ }^{2}$, estudo de caso ${ }^{3}$, aprendizagem entre pares ou times, têm importância. Contudo, não podem ser consideradas, em sua totalidade, um processo inovador, pois inovação e a construção do conhecimento, através da construção do novo, é fazer diferente do que era feito, construindo um novo processo de aprendizagem.

Para compreender melhor o contexto em pauta, foi realizado uma pesquisa exploratória sobre o tema, com a finalidade de verificar as pesquisas já existentes. Nessa perspectiva, Fernandes e Morosini (2014) destacam a importância de buscar conhecer a produção científica sobre o tema a ser estudado. A esse respeito, as autoras ressaltam que o

[e]stado de conhecimento é identificação, registro, categorização que levem à reflexão e síntese sobre a produção cientifica de uma determinada área, em um determinado espaço de tempo, congregando periódicos, teses, dissertações e livros sobre uma temática específica. Uma característica a destacar é a sua contribuição para a presença do novo (Fernandes; Morosini, 2014, p. 155).

O processo de inovação e aprendizado tratado na fundamentação teórica proporciona um entendimento prévio do que será identificado nas produções selecionadas sobre a forma dos descritos da pesquisa com intuito de facilitar a compreensão deste estudo.

A partir da temática supramencionada, busca-se elaborar um estudo que a aborde relacionando com os registros encontrados em periódicos da CAPES. Com isso, o objetivo é fazer um levantamento das pesquisas que estão sendo realizadas sobre o tema inovação no ensino superior, por isso realizou-se uma busca de produções científicas disponíveis no catálogo de teses e dissertações da CAPES. Optou-se por fazer a pesquisa somente sobre dissertações que correspondem ao período de 2015 a 2019. Sua realização é de suma importância para o pesquisador conhecer as produções científicas produzidas, bem como para refletir sobre a temática em questão. Com o intuito de reconhecer que pesquisas estão sendo desenvolvidas sobre a temática inovação no curso de ciências contábeis.

Morosini (2015, p. 102), estado de conhecimento é a identificação, registro, categorização, que levem à reflexão e síntese sobre a produção científica de uma determinada área, em um determinado espaço de tempo [...].

Nesse processo, muitas vezes, a dissertação apresenta o termo de busca em sua linha de pesquisa ou em sua área de

\footnotetext{
${ }^{2}$ O problema, nessa perspectiva, não é formulado de antemão, mas irá emergir da realidade estudada, a partir da observação da mesma, através de trabalho em campo, leitura de textos atualizados, de jornais, de revistas e de relatórios de pesquisa, entre outros (Grillo; Lima, 2008).

${ }^{3} \mathrm{O}$ professor esclarece os objetivos da atividade e a dinâmica a ser adotada e, em seguida, propõe a situação detalhada, real ou fictícia, para exercício coletivo, utilizando-se dos conhecimentos dos participantes. Recomenda aos alunos que, enquanto tomam a situação, façam mentalmente indagações e destaquem aspectos considerados importantes (Grillo; Lima, 2008, p. 135).
} 
conhecimento, sem que o objeto de estudo ou de pesquisa seja o termo investigado. Desse modo, realizou-se um mapeamento das produções científicas, com abordagem qualitativa e análise de conteúdo proposta por Bardin (2009) Desse modo, foi necessário fazer uma leitura mais cuidadosa do resumo de cada uma dessas produções, para verificar se de fato possuíam o tema de interesse. Essa pesquisa foi realizada a partir dos seguintes descritores: Curso de Ciências Contábeis, Ensino Superior e Inovação no Ensino, como mencionado na Figura 1.

Figura 1 - Descritores da pesquisa.

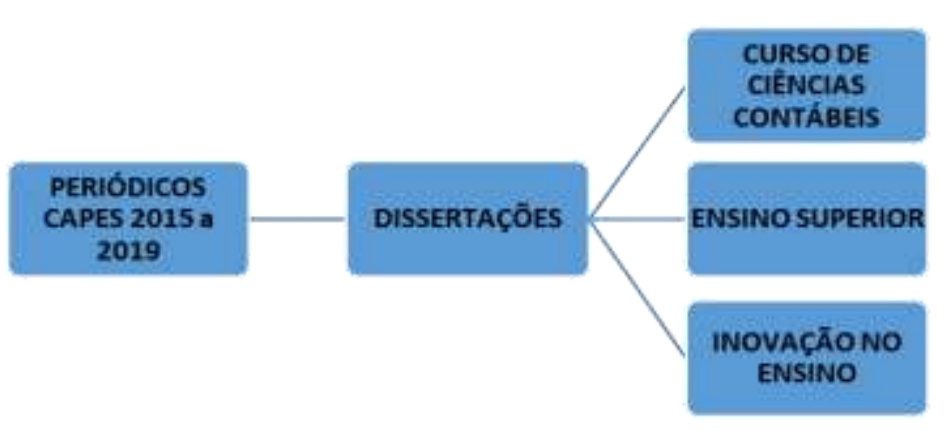

Fonte: Autores (2020).

O número de trabalhos que se aproximam das temáticas e o número de trabalhos sobre a temática estão dispostos na Tabela 1

Figura 2 - Fluxograma.

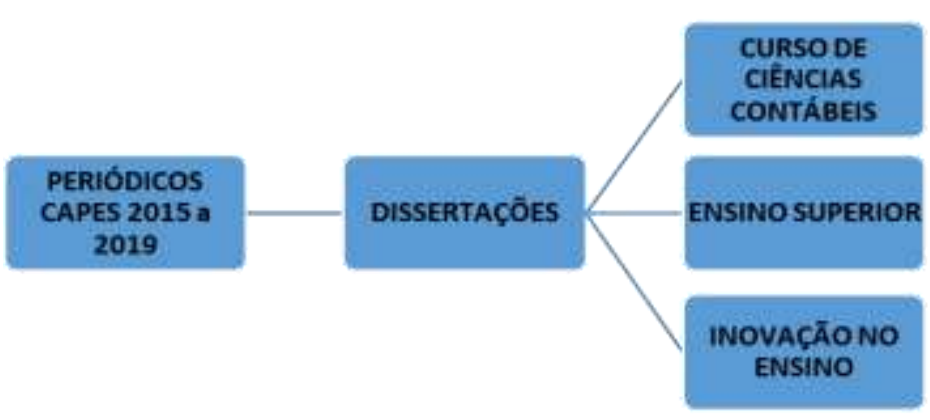

Fonte: Autores (2020). 
Tabela 1 - Produções científicas encontradas no catálogo de teses e dissertações da CAPES, ano a ano, entre o período de 2015 a 2019.

\begin{tabular}{|c|c|c|}
\hline Ano de publicação & $\begin{array}{c}\mathrm{N}^{\circ} \text { de trabalhos que se aproximam } \\
\text { das temáticas }\end{array}$ & $\mathrm{N}^{\mathrm{o}}$ de trabalhos sobre a temática \\
\hline 2015 & 11 & 0 \\
\hline 2016 & 4 & 2 \\
\hline 2017 & 2 & 0 \\
\hline 2018 & 0 & 0 \\
\hline 2019 & 0 & 0 \\
\hline Total & 17 & 2 \\
\hline
\end{tabular}

Tabela 2 - Número total de dissertações pesquisadas por descritor.

\begin{tabular}{ccc}
\hline Descritor & Dissertações & $\%$ \\
\hline Curso de ciências contábeis & 340 & $26 \%$ \\
Ensino Superior & 560 & $43 \%$ \\
Inovação no Ensino & 410 & $31 \%$ \\
\hline Total & 1.310 & $100 \%$ \\
\hline
\end{tabular}

Fonte: Autores (2020).

No contexto investigativo, mencionado na Tabela 1, foi feito uma busca referindo-se ao tema como um todo. Nele foram encontrados 17 trabalhos, que se aproximam com o tema, e 2 trabalhos com relevância sobre a temática. Desta investigação, inicia-se uma pesquisa pelo descritos Curso de Ciências Contábeis, Ensino Superior e Inovação no Ensino, sendo descrito na Tabela 2 .

$\mathrm{Na}$ Tabela 2, é possível observar que foram encontradas 1.310 dissertações, entre os descritores pesquisados. Por se tratar de um termo mais generalista, o descritor Ensino Superior aparece com superioridade em relação aos demais, com 560 dissertações, tendo um índice acima de $60 \%$ do total de trabalhos encontrados. Em outro extremo, está o descritor Curso de Ciências Contábeis, o qual representou menos de $26 \%$ do total de trabalhos pesquisados. O descritor Ensino Superior apresenta 560 dissertações, representando $43 \%$ do total dos descritos, já o descritor Inovação no Ensino tem sua representatividade de 43\%. Assim, em uma primeira avaliação a respeito de como está sendo trabalhado, em termos de pesquisa, é possível afirmar que o tema Inovação no Ensino de Ciências Contábeis carece de maiores investigações. Como o número de trabalhos sobre o tema é ínfimo, optou-se em analisar com mais detalhamento os trabalhos que possuem alguma afinidade sobre o tema e foi contabilizado 17 pesquisas de dissertação sobre isso. Tratou-se, então, de verificar a quantidade de trabalhos (dissertações) que possuem um vínculo maior com os objetivos da presente pesquisa (Tabela 3).

Tabela 3 - Número total de dissertações com temáticas convergentes.

\begin{tabular}{lcc}
\hline Descritor & Dissertações & $\%$ \\
\hline Curso de ciências contábeis & 3 & $18 \%$ \\
Ensino Superior & 8 & $47 \%$ \\
Inovação no Ensino & 6 & $35 \%$ \\
\hline Total & 17 & $100 \%$ \\
\hline
\end{tabular}

Fonte: Autores (2020).

Através de um estudo mais detalhado do resumo e referencial teórico desses trabalhos, foi possível identificar aqueles que possuem algumas semelhanças com a proposta de pesquisa aqui desenvolvida. Os descritores curso de Ciências Contábeis, 
Ensino Superior, Inovação no Ensino mantiveram um índice elevado em relação aos demais, atingindo índice superior à 47\% em relação aos trabalhos que mais se aproximaram do tema da pesquisa. Quando estudado sua relação com o tema da pesquisa, o descritor curso de Ciências Contábeis apresentou índice de $18 \%$.

O resultado da busca mostrou que são exíguas a existência trabalhos publicados nos anos de 2015 a 2019 diretamente relacionados sobre o tema. Foram encontrados 2 trabalhos de dissertação referente ao tema, do ano de 2016. Tais trabalhos foram descritos na Tabela 4, separados por título, autor e o ano de publicação.

Tabela 4 - Produções científicas encontradas no catálogo de teses e dissertações da CAPES entre 2015 e 2019 diretamente sobre o tema.

\begin{tabular}{ccc}
\hline Título & Autor & Ano \\
\hline $\begin{array}{c}\text { As tecnologias digitais da informação e comunicação } \\
\text { na docência universitária nos cursos de administração e } \\
\text { ciências contábeis }\end{array}$ & VESPASIANO, Luce Mary & 2016 \\
$\begin{array}{c}\text { Adoção de modelos inovadores no ensino superior na } \\
\text { perspectiva da teoria da dependência de recursos }\end{array}$ & $\begin{array}{c}\text { COSTA, Gracilene } \\
\text { Maria Silva dos Santos }\end{array}$ & 2016 \\
\hline
\end{tabular}

Fonte: Autores (2020).

A primeira dissertação, As tecnologias digitais da informação e comunicação na docência universitária nos cursos de administração e ciências contábeis (2016), tem o objetivo investigar o que os professores de cursos de Administração e Ciências Contábeis relatam a respeito da participação de tecnologias digitais de informação e comunicação adotadas na docência. Dentro deste conceito, realizou-se um estudo dos paradigmas científicos e tecnológicos e suas influências nos conhecimentos dos professores e no contexto educacional. Também abordou tal importância ao conhecimento do professor universitário, perspectivando com a necessidade de desenvolver competências pedagógico-digital para a integração das Tecnologias Digitais de Informação e Comunicação (TDIC) no ensino aprendizagem, ou seja, que transcenda um conhecimento fragmentário, tecnicista e reducionista observado no paradigma atual.

Nesta dissertação foi utilizada uma perspectiva relacionada a integração das TDIC na docência universitária, tem como suporte teórico o esquema teórico intitulado Conhecimento Pedagógico-Tecnológico de Conteúdo. Esse estudo caracterizou-se por uma abordagem mista. Fizeram parte da pesquisa 47 professores do ensino superior, de uma instituição de Minas Gerais e uma de São Paulo. Todos os dados foram coletados foram levantados através de um questionário e entrevista, e analisados por meio do método estatístico multidimensional viabilizado pelo software - Classificação Hierárquica, Implicativa e Coesiva -, que gerou árvores de similaridade, em que foi possível estabelecer relação entre os professores pesquisados e as variáveis do estudo. A análise de conteúdo na perspectiva de Bardin (2007).

Vespasiano (2016) apontam que as instituições de ensino superior, inseridas na pesquisa, possuem boa infraestrutura e promovem cursos de formação de professores. na maior parte dos professores investigados já participaram de cursos em TDIC. Porém, a pesquisa sugere que esses fatores não estão sendo suficientes para promover a integração das TDIC no ensinoaprendizagem.

Nesta pesquisa também é evidenciado que os professores ainda estão trazendo as TDIC para a sala de aula com o viés técnico, com foco no ensino e não levando em conta o ensino-aprendizagem. Conforme os estudos teóricos sugerem, isso é importante para uma melhor exploração das potencialidades das TDIC, segundo Vespasiano (2016). Outro resultado apontado pelas análises é que os professores, de forma geral, reconhecem a importância e as potencialidades das TDIC, no contexto educacional, como ressignificação de metodologias tradicionais de ensino. 
A pesquisa de Vespasiano (2016) trouxe a evidência de que ensinar também é desenvolver a competência pedagógicodigital, para a integração das TDIC no ensino-aprendizagem, de forma a atender as demandas do século XXI, sendo uma tarefa complexa. Exigindo do professor a criação de conhecimentos tecnológicos, pedagógico e de conteúdo tendo uma visão articulada do seu todo. Dessa forma, a investigação trouxe indícios de que o conhecimento do professor ainda está limitado, por implicações de paradigmas e em decorrência de dificuldades relativas à formação para o exercício da profissão.

A segunda dissertação, tem o intuito de uma adoção aos modelos inovadores no ensino superior na perspectiva da teoria de dependência de recursos, de Costa (2016), evidencia que, especialmente, a educação precisa acompanhar, permanentemente, as transformações que vem acontecendo na sociedade. Metodologias tradicionais, são alvo de profunda críticas, tendo em vista que nelas o aluno assume o papel de mero expectador e assimilador do conhecimento. A partir dessas críticas e de movimentos, Metodologias Ativas foram criadas e trazem uma perspectiva inovadora para. Sendo sua principal premissa ensinar o aluno a aprender, trazendo o aluno ao centro do processo de ensino-aprendizagem.

Neste contexto, Costa (2016) descreve que o aluno passa a ser responsável pelo aprendizado, sendo dotado de autonomia e é incentivado pelo professor, cujo o papel do professor passa a ser o mediador do conhecimento, auxiliando no desenvolvimento de um senso crítico. O estudante passa a tem a oportunidade de obter habilidades, através de um métodos que envolve teoria e prática de forma mais integrada, e lidar com o desafio de vivenciar problemas da vida real, com os quais poderá ter contato após sua formação.

A adoção de metodologias ativas, segundo a autora, implica em grandes mudanças na gestão de universidades, no ponto de vista da gestão dos recursos para à viabilização das metodologias. Diante desse problema, a pesquisa de Costa (2016) se caracteriza como um estudo de caso, cuja pretensão foi identificar as práticas e os desafios na gestão de um campus universitário que adota, integralmente, as metodologias ativas.

Explorando essa problemática na organização, com objeto da análise da autora foi o Campus Lagarto da Universidade Federal de Sergipe (UFS). Foi utilizada a Teoria da Dependência de Recursos. Trata-se de uma pesquisa qualitativa, sendo realizadas entrevistas em profundidade com gestores do referido campus e da Universidade Federal de Sergipe. Além disso, foram utilizadas as técnicas de coleta de dados baseadas na observação participante, pesquisa documental e, para avaliação e interpretação dos resultados obtidos, foi usada a análise de discurso, tendo em vista a busca de uma compreensão contextualizada da problemática proposta pela pesquisa. Considero que o. que os trabalhos que foram selecionados foram os que mas se identifica com o tema da pesquisa, mas mesmo assim eles não tratam um abordagem direta ao estudo inovação aplicada ao ensino superior de graduação em ciências contábeis.

\section{Conclusão}

Buscou-se, nesta pesquisa do estado do conhecimento, problematizar sobre o tema inovação no Curso de Ciências Contábeis e a inter-relação com seus aspectos de ensino superior e de inovação ao ensino, tendo em vista a o processo formativo. Ao analisar os trabalhos evidenciou-se que existem poucas publicações com o referido tema, ainda é preciso ampliar os estudos e discussões acerca da inovação no curso de ciências contábeis no que se refere aos descritores Ciências Contábeis, Ensino Superior e Inovação no Ensino, partindo do pressuposto que são elementos formativos essenciais no que se refere ao tema pesquisado. É de suma importância partir destes conceitos acerca dos aspectos conceituais para o aprofundamento deste estudo no que se refere a este novo processo de ensinar.

Nessa análise, também, evidenciou-se que a realização de uma pesquisa envolvendo os descritores mencionados é de extrema relevância, justamente porque possibilita pensar e propor saídas para que haja a inovação no Curso de Ciências Contábeis. Ao partir do pressuposto que a inovação no ensino em geral e no ensino superior é o caminhos para um ensino e aprendizagem eficaz e de qualidade, faz-se essencial que os aspectos teórico-práticos sobre o conhecimento e a compreensão 
acerca dos elementos que envolvem a inovação no ensino superior sejam pesquisados e analisados. Por isso, foi realizado o percurso teórico e de busca no catálogo da CAPES aqui apresentado.

A partir dos trabalhos analisados, então, compreende-se que apontam novos olhares para o Ensino Superior, Inovação no Ensino e Ciências Contábeis, uma vez que é perceptível a fragmentação e fragilidades sobre o tema inovação ao Curso de Ciências Contábeis e o quanto é complexo compreender como acontece este processo de inovação e suas inter-relações. Assim, é de suma relevância a relação universidade, entender como este processo acontece e como o curso poderá possibilitar uma interação entre a prática e a teoria que está sendo estudando. Em relação a inovação, não basta apenas estudá-la, é preciso vivenciá-la para compreendê-la, efetivamente, em suas concepções, dinâmicas, entraves e avanços, mas, sobretudo, em suas potencialidades e possibilidades.

Portanto, o levantamento destas produções acadêmicas nos periódicos da CAPES, no período de 2015 a 2019 , apresentaram um ponto de partida para aprofundar as reflexões acerca da inovação no Curso de Ciências Contábeis, sendo que foi encontrado dois trabalhos que se aproximam do tema de estudo. Desse modo, o levantamento realizado mostrou que é necessário investimento em pequisas dessa natureza, para que possa contribuir para a inovação das prática pedagógica aplicadas no ambito interno e externo das instituições de ensino que disponibilizam o Curso de Graduação em Ciências Contábeis.

\section{Referências}

Anastasiou, L. das G. C., \& Alves, Pessate (Orgs.). Processos de ensinagem na universidade: pressupostos para as estratégias de trabalho em aula. (10a ed.), Editora Univille, 2015.

Bacich, L., \& Moran. J. (Org.). Metodologias ativas para uma educação inovadora: uma abordagem téorico-prática. Penso.

Bardin, L. Análise de Conteúdo. (70a ed.).

Bardin, L. Análise de Conteúdo. Edições 70.

Berbel, N. A. N. As metodologias ativas e a promoção da autonomia de estudantes. Semina: Ciências sociais e humanas. 32(1), 25-40. <http://www.uel.br/revistas/uel/index.php/seminasoc/article/view/10326/0>. Acesso em: 28 nov. 2019.

Behrens, M. A. Tecnologia interativa a serviço da aprendizagem colaborativa num paradigma emergente. Interação das Tecnologias na Educação / Secretária de Educação a Distância. Brasília: Ministério da Educação.

Costa, G. \& Maria S. dos S. Adoção de modelos inovadores no ensino superior na perspectiva da teoria da dependência de recursos. 2016.

Cunha, M. I. da. Inovações na educação superior: impactos na prática pedagógica e nos saberes da docência. 29(97), 87-101, 2016. Dissertação (Mestrado em Administração) - Universidade Federal de Sergipe, São Cristóvão, SE, 2016.

Charlot B. Formação de professores: a pesquisa e a política educacional. In: Pimenta. S. G., Ghedin E. (Orgs.). Professor reflexivo no Brasil: gênese e crítica de um conceito. (6̧a ed.), 89-109.

Ens, R. T., \& Romanowski, J. P. As pesquisas denominadas do tipo “estado da arte” em educação. Diálogo Educacional, 6(19), 37-50.

Freire, P. Pedagogia da autonomia: saberes necessários à prática educativa. Paz e Terra.

Fernandes, C. M. B., \& Morosini, M. C. Estado do conhecimento: conceitos, finalidades e interlocuções. Educação por escrito. 5(2), $154-164$.

Grillo, M. C., \& Lima, V. M. do R. A gestão da aula universitária na PUCRS. EDIPUCRS.

Masetto, M. T. Competência pedagógica do professor universitário. Summus Editorial.

Masetto, M. T. Inovação no ensino superior. Edições Loyola.

Morosini, M. Estado do conhecimento e questões de campo científico. Revista da Educação, 40(1).

Morosini, M. da C, \& Nascimento, L. M do. Internacionalização da Educação Superior no Brasil. Educação em Revista, 33.

Tidd, J., Bessant, J., \& Pavitt, K. Gestão da Inovação. Tradução Elizamari Rodrigues Becker et al. Bookman.

Pimenta, S. G., \& Anastasiou, L. das G. C. Docência no Ensino Superior. (5a ed.), Cortez. 
Research, Society and Development, v. 10, n. 6, e5610615422, 2021

(CC BY 4.0) | ISSN 2525-3409 | DOI: http://dx.doi.org/10.33448/rsd-v10i6.15422

Toebe, I. C. D. Políticas públicas para integração de tecnologias educacionais na formação inicial de professores. 2016. 170f. Dissertação (Mestrado em Educação) - Universidade Federal de Santa Maria <https:// repositorio.ufsm.br/handle/1/7291>.

Vespasiano, L. M. As tecnologias da informação e comunicação na docência universitária nos cursos de administração e ciências contábeis. 2016. Dissertação (Mestrado em Educação) - Programa de Pós-Graduação em Educação, Universidade Federal do Triângulo Mineiro. 